\title{
Allopurinol and 5-aminosalicylic acid influence thiopurine-induced hepatotoxicity in vitro
}

\author{
Mark M. T. J. Broekman • Hennie M. J. Roelofs • Dennis R. Wong • \\ Mariska Kerstholt • Alex Leijten • Frank Hoentjen • \\ Wilbert H. M. Peters • Geert J. A. Wanten • Dirk J. de Jong
}

Received: 29 September 2014 / Accepted: 7 April 2015 /Published online: 28 April 2015

(C) The Author(s) 2015. This article is published with open access at Springerlink.com

\begin{abstract}
Introduction The use of thiopurines is frequently accompanied by hepatotoxicity. Studies on hepatocyte cultures showed a time- and dose-dependent increase of thiopurine toxicity. 5-Aminosalicylic acid (5-ASA) and allopurinol can influence thiopurine metabolism; however, it is unknown whether this affects in vitro cytotoxicity.

Methods Human hepatoma cells (Huh7, HepG2 and HepaRG) were incubated with increasing concentrations of thiopurines, 5-ASA or allopurinol. Watersoluble tetrazolium salt-1 (WST-1) cytotoxicity assays were used to calculate cell survival curves and half maximal inhibitory concentrations $\left(\mathrm{IC}_{50}\right)$. Combination experiments with thiopurines with a fixed dose of $200 \mu \mathrm{M} 5$-ASA or $100 \mu \mathrm{M}$ allopurinol were conducted in HepaRG cells. Caspase-3/7 activation was evaluated, and single cell electrophoresis analysis was performed. Results A time- and dose-related cytotoxic effect was seen with azathioprine (AZA) in all hepatoma cells, whereas Huh7 and HepG2 cells did not show toxicity to 6-mercaptopurine (6-MP). HepaRG cells expressed
\end{abstract}

M. M. T. J. Broekman $(\bowtie) \cdot$ H. M. J. Roelofs •

M. Kerstholt • A. Leijten - F. Hoentjen - W. H. M. Peters •

G. J. A. Wanten · D. J. de Jong

Department of Gastroenterology, Radboud University

Nijmegen Medical Center, 455, P.O. Box 9101, 6500

HB Nijmegen, The Netherlands

e-mail: mark.broekman@radboudumc.nl

D. R. Wong

Department of Clinical Pharmacy \& Toxicology,

Orbis Medical Center, Sittard-Geleen, The Netherlands the highest levels of drug metabolising enzymes, and therefore, combination experiments were conducted in HepaRG cells. Addition of a non-toxic dose of allopurinol resulted in a twofold to threefold increased cytotoxicity of all thiopurines, which seemed to be mediated by apoptosis/DNA damage.

Conclusion The addition of allopurinol to thiopurines leads to a two-threefold increased cytotoxicity in HepaRG cells.

Keywords 5-Aminosalicylic acid - Allopurinol . 6-Mercaptopurine $\cdot$ Thioguanine Azathioprine . HepaRG · HepG2 · Huh7 · Cytotoxicity · Thiopurines

$\begin{array}{ll}\text { Abbreviations } \\ \text { 5-ASA } & \text { 5-Aminosalicylic acid } \\ \text { 6-MP } & \text { 6-Mercaptopurine } \\ \text { 6-TGN } & \text { 6-Thioguanine nucleotide } \\ \text { AZA } & \text { Azathioprine } \\ \text { TG } & \text { Thioguanine } \\ \text { 6-MMP } & \text { 6-Methylmercaptopurine } \\ \text { TMPT } & \text { Thiopurine-S-methyltransferase } \\ \text { XO } & \text { Xanthine oxidase } \\ \text { DMSO } & \text { Dimethyl sulfoxide }\end{array}$

\section{Introduction}

The metabolism of azathioprine (AZA) and 6mercaptopurine (6-MP) is complex and involves multiple enzymatic steps, before the pharmacologically 
active substrate 6-thioguanine nucleotide (6-TGN) is produced (see Fig. 1). During this process, side products such as 6-methylmercaptopurine ribonucleotides (6MMP) and thiouric acid are also formed. The metabolism of thioguanine (TG) is less complex with the main pathway resulting in a more direct conversion to 6TGN. Several factors may influence thiopurine metabolism such as genetic variants in the thiopurine-Smethyltransferase (TPMT) gene and the use of concomitant drugs (Sahasranaman et al. 2008).

With respect to inflammatory bowel disease (IBD), the most relevant drugs that can influence thiopurine metabolism are 5-aminosalicylic acid (5-ASA) and allopurinol. Allopurinol, a strong xanthine oxidase (XO) and TPMT inhibitor, reduces 6-MMP formation (Blaker et al. 2013). The combination of allopurinol with a tailored dosage of AZA or 6-MP is a potent strategy in patients with a skewed metabolism towards the cytotoxic 6MMP formation. Hoentjen et al. showed a significant reduction of 6-MMP levels from $10,110 \mathrm{pmol} / 8 \times 10^{8} \mathrm{red}$ blood cell (RBC) with monotherapy to $265 \mathrm{pmol} / 8 \times 10^{8}$ $\mathrm{RBC}$ with combination therapy and significant increase of 6-TGN levels from 145 to $271 \mathrm{pmol} / 8 \times 10^{8} \mathrm{RBC}$ (Hoentjen et al. 2013). Thiopurines and 5-ASA exert their disease-modifying effect by different mechanisms, yet 5-ASA can interfere in thiopurine metabolism by a non-competitive inhibition of TPMT (Szumlanski and Weinshilboum 1995). Therefore, co-administration can lead to a decreased production of 6-MMP and increase of the therapeutic active 6-TGN (Lowry et al. 2001; Dewit et al. 2002; de Graaf et al. 2010).

Studies to explore hepatotoxicity in humans on a cellular level are costly and have major ethical considerations. In vitro studies with primary cultures of hepatocytes or hepatoma cell lines are an ethical and feasible alternative for exploring drug toxicity. Previous in vitro studies demonstrated a time- and dose-dependent toxicity of AZA, 6-MP and 6-TG in HepaRG and HepG2 cells (Petit et al. 2008; de Vries et al. 2012). In this study, we aim to explore the effects of the addition of 5-ASA or allopurinol on thiopurine-induced hepatotoxicity.

\section{Materials and methods}

HepG2 and Huh7 cells have been used extensively in in vitro experiments so far; therefore, we tested cytotoxicity in these hepatoma cell lines as well as in the more recently developed HepaRG cell line (Andersson et al. 2012). First, we assessed individual cytotoxicity of AZA, 6-MP and TG in all three cell lines. Next, we tested these cell lines for the expression of important drug metabolising enzymes and used the hepatoma cell line with the highest expression of drug metabolising enzymes to explore the influence of 5-ASA and allopurinol on cytotoxicity of thiopurines.

\section{Cell culture}

Hepatocyte-differentiated HepaRG cells (Invitrogen ${ }^{\mathrm{TM}}$, Paisly, UK), HepG2 (HB-8065'M American Type Culture Collection, Rockville, USA) and Huh7 cells (JCRB0403, Cell Resource Center for Biomedical Research, Tohoku University, Japan) were used and cultured as described previously (Parent et al. 2004; de Vries et al. 2012). Cells were seeded into 96-well flat bottom microplates at a density of $1.48 \times 10^{5}$ cells $/ \mathrm{cm}^{2}$ for the HepG2 and Huh7 cells and $4.5 \times 10^{5}$ cells $/ \mathrm{cm}^{2}$ for

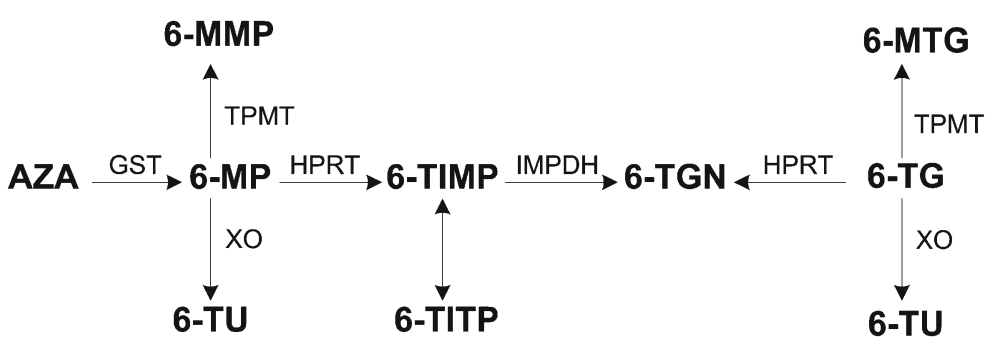

Fig. 1 Simplified overview of thiopurine metabolism. Azathioprine $(A Z A)$ is converted by glutathione S-transferase $(G S T)$ in 6-mercaptopurine (6-MP). 6-MP can be methylated by thiopurine S-methyl transferase (TPMT) into 6-methyl mercaptopurine $(6-M M P)$, oxidised by xanthine oxidase $(X O)$ into 6-thiouric acid (6-TU) or metabolised by hypoxanthine-guanine phosphoribosyltransferase $(H P R T)$ into 6-thioinosine

monophosphate (6-TIMP). Next, 6-TIMP can be phosphorylated into 6-thioinosine triphosphate (6-TITP) or metabolised into the pharmacological active 6-thioguanine nucleotides $(6-T G N)$. Besides metabolised into 6-TGN by HPRT, 6-thioguanine $(T G)$ can be oxidised by XO into 6-TU or methylated by TMPT into 6methyl thioguanine (6-MTG) 
the HepaRG cells according to the manufacturer's protocol. After 24-h incubation, the medium was replaced by differentiation medium, being growth medium supplemented with $2.0 \%(v / v)$ dimethyl sulfoxide (DMSO) (Sigma-Aldrich B.V.). Addition of DMSO is according to the protocol of growing HepaRG cells. To increase uniformity of the experiments, we also used differentiation medium in HepG2 and Huh7 cell cultures.

Incubations with drugs

On the fourth day after seeding, cells were incubated with one of the following test substances; AZA, 6-MP, 5-ASA, allopurinol (all from Sigma-Aldrich B.V.) or TG (Alfa Aesar GmbH \& Co KG, Karlsruhe, Germany) in concentrations ranging from $0.5 \mu \mathrm{M}$ to $4 \mathrm{mM}$. For the combination experiments, a fixed nontoxic dose of $200 \mu \mathrm{M}$ 5-ASA or $100 \mu \mathrm{M}$ allopurinol was used in combination with the same range of thiopurines for 24,48 or $72 \mathrm{~h}$. In order to mimic daily drug administration, medium with drugs was refreshed every $24 \mathrm{~h}$.

\section{Evaluation of cytotoxicity}

Water-soluble tetrazolium salt-1 (WST-1) assays (Roche Diagnostics Nederland BV, Almere, the Netherlands) were performed after 24,48 or $72 \mathrm{~h}$ of incubation with the drugs. The WST assay is based on the ability of viable cells to cleave the tetrazolium salt WST, which was measured with a Tecan Infinite m200PRO plate reader (Tecan, Giessen, the Netherlands) as described previously (de Vries et al. 2012). Three independent experiments were conducted in triplicate.

\section{Evaluation of drug metabolising enzymes}

Protein expression of important drug metabolising enzymes was measured for two purposes: first to select the cell line with the highest expression (and therefore best comparability with human hepatocytes) and second to quantify any influence of adding DMSO to the culture medium of HepG2 and Huh7 cells. The following enzymes were analysed: UDP-glucuronosyltransferase 1A (UGT1A), cytochrome-P450 3A4 (CYP3A4), glutathione S-transferase alpha (GSTAlpha), mu (GSTMu) and theta (GSTTheta) (Eklund et al. 2006). These enzymes were chosen because of their role in thiopurine metabolism (GSTAlpha and GSTMu) or their important role in drug metabolism in general. Cells were seeded in $25 \mathrm{~cm}^{2}$ flasks, and after $24 \mathrm{~h}$ of culturing, half of the flasks were supplemented with differentiation medium (group DMSO+), while the other half received standard William's E growth medium (group DMSO-). On days 0,3 and 7, cells were harvested and homogenised using lysis buffer, consisting of $0.25 \mathrm{M}$ saccharose, $20 \mathrm{mM}$ Tris- $\mathrm{HCl} \mathrm{pH} 7.4,1 \mathrm{mM}$ dithiothreitol (DTT) and $1 \%$ Triton X-100 and lysates frozen at $-20{ }^{\circ} \mathrm{C}$ until use. Total amount of protein was assessed according to the Lowry procedure (Lowry et al. 1951). Homogenates (25 $\mu \mathrm{g}$ protein) were loaded on 8,10 or $12 \%$ SDS polyacrylamide gels for UGT, CYP3A4 or GST analyses, respectively. After electrophoresis, proteins were transferred to nitrocellulose (Whatman GMBH, Dassel, Germany) using a semi-dry blotter (V20-SDB, Scie-Plas, Cambridge, UK). Non-specific binding was blocked with $1 \%$ gelatine in phosphate-buffered saline (PBS)/Tween $20(0.05 \%, v / v)$. The following primary monoclonal antibodies were added: CYP3A4 (kind gift from Dr. P. Kremer, Université de Liège, Belgium), GST class Theta T1-1 (purchased from Dr. E. Juronen, Tartu, Estonia), UGT1A, GSTAlpha (A1-2) and GSTMu (all developed in our laboratory) (Peters et al. 1987; Peters et al. 1990; Peters et al. 1992). $\beta$-Actin (1:10,000, Sigma-Aldrich B.V.) was used as protein loading control. After incubation and washing, polyclonal rabbit anti-mouse peroxidase-conjugated second antibodies (Dako Diagnostics, Glostrup, Denmark) were added. Immunoreactive proteins were visualised with $0.1 \%$ $(w / v)$ 3,3-diaminobenzidine, $5 \mathrm{mM}$ imidazole, $2 \mathrm{mM}$ cobalt chloride hexahydrate and $8 \mu \mathrm{L} 30 \%$ hydrogen peroxide in $50 \mathrm{~mL}$ PBS.

TPMT enzyme activity and polymorphism

To exclude influence caused by variation in TPMT activity, we analysed TPMT polymorphisms as well as TPMT enzyme activity. TPMT enzyme activity was assessed by high-performance liquid chromatography (HPLC) as described previously (Ford and Berg 2003). Genotyping of the three common variants in the TPMT gene $\left(T P M T^{*} 2\right.$, *3A and *3B) was performed according to the manufacturer's protocol using Taqman SNP genotyping assays (Life Technologies, Bleiswijk, the Netherlands, (TPMT*2: rs 1800462 , assay ID C_12091552_30; TPMT*3B: rs1800460, assay ID C 30634116_20; TPMT*3A: rs1142345, assay ID C__19567_20). Signals were detected with 7500 Fast 

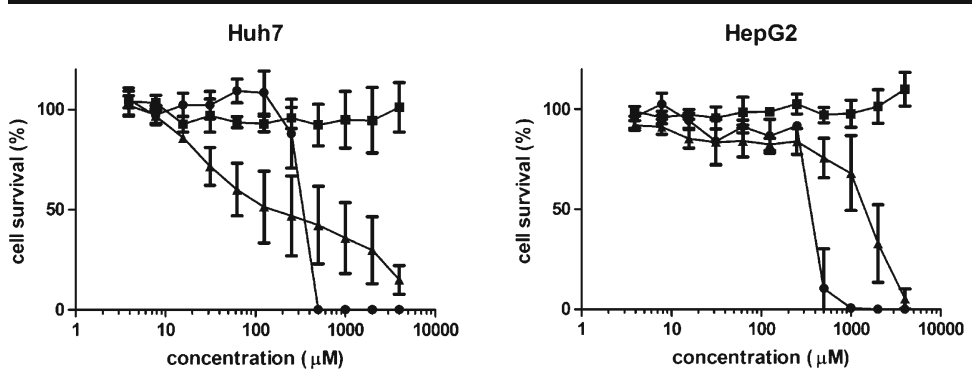

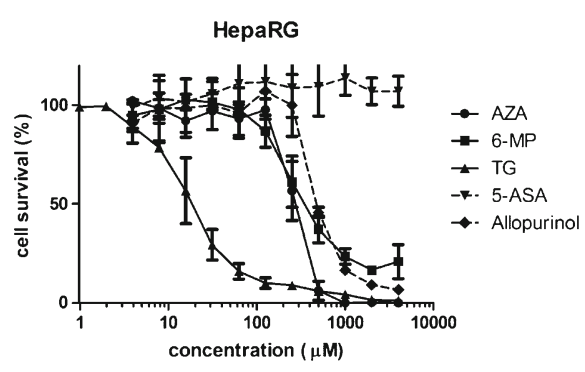

Fig. 2 Cell survival after incubation of Huh7, HepG2 and HepaRG cells with azathioprine $(A Z A), 6$-mercaptopurine (6$M P)$ or thioguanine $(T G)$ for $72 \mathrm{~h}$. In the HepaRG cells, 5- aminosalicylic acid (5-ASA) and allopurinol were also tested. Values are means with SEM from three independent experiments, performed in triplicate. SEM standard error of the mean
Real-Time PCR system (Life Technologies) and subsequently analysed using the Allelic Discrimination software version 1.4 (Life Technologies).

Thiopurine metabolite assessment

6-MMP and 6-TGN were assessed in cell lysates by a HPLC method as described by Dervieux et al. (Dervieux and Boulieu 1998). Metabolite analysis was only done for AZA, since the pharmacological action is based on the release of 6-MP. We assumed that if AZA is intracellular metabolised, 6MP will be too. For this purpose, HepaRG cells were incubated with $600 \mu \mathrm{M}$ AZA for $10 \mathrm{~h}$; subsequently, the cells were washed with PBS $0.9 \%$, harvested, homogenised and stored at $-20{ }^{\circ} \mathrm{C}$ until use.

\section{Caspase-3/7 activation}

Caspase-3/7 activation was tested in HepaRG cells treated with AZA with and without 5-ASA or allopurinol with the Apo-ONE ${ }^{\circledR}$ Homogeneous Caspase-3/7 Assay (Promega) according to the manufacturer's protocol. Briefly, HepaRG cells were seeded in a flat-bottom 96well plate in a density of 20,000 cells/well. Cells were incubated with only medium (control), AZA $(70 \mu \mathrm{M})$, 5-ASA $(200 \mu \mathrm{M})$, allopurinol $(100 \mu \mathrm{M})$, a combination of AZA+5-ASA, a combination of AZA+allopurinol or staurosporine $(2 \mu \mathrm{M})$ (positive control). After $24 \mathrm{~h}$, Apo-one reagent was added. Caspase- $3 / 7$ activation was measured after $6 \mathrm{~h}$ on a Tecan Infinite m200PRO plate reader (Tecan, Giessen, the Netherlands). Two experiments were performed in triplicate. The control was set as reference to calculate differences in caspase$3 / 7$ activation.
Table $1 \mathrm{IC}_{50}$ values in HepG2, HepaRG and Huh7 cells after 24, 48 or $72 \mathrm{~h}$ exposure to thiopurines, 5-ASA or allopurinol

Values are expressed in $\mu \mathrm{M}$ with $95 \%$ confidence interval.

Significantly different $(P<0.05)^{*}$ or $(P<0.01)^{* *}$ compared to $24-\mathrm{h}$ shorter incubation

$A Z A$ azathioprine, 6-MP 6-mercaptopurine, $T G$ thioguanine, 5$A S A$ 5-aminosalicylic acid, $I C_{50}$ half maximal inhibitory concentrations, n.r. $\mathrm{IC}_{50}$ not reached, $95 \%$ CI $95 \%$ confidence interval

\begin{tabular}{lllll}
\hline & & $24 \mathrm{~h}$ & $48 \mathrm{~h}$ & $72 \mathrm{~h}$ \\
& & $\mathrm{IC}_{50}(95 \% \mathrm{CI})$ & $\mathrm{IC}_{50}(95 \% \mathrm{CI})$ & $\mathrm{IC}_{50}(95 \% \mathrm{CI})$ \\
\hline HepG2 & AZA & $572(520-628)$ & $406(333-495)^{* *}$ & $363(315-419)$ \\
& 6-MP & n.r. & n.r. & n.r. \\
& TG & n.r. & $1746(1258-2422)^{* *}$ & $1134(812-1585)$ \\
Huh7 & AZA & $464(431-501)$ & $400(314-509)$ & $307(188-501)$ \\
& 6-MP & n.r. & n.r. & n.r. \\
& TG & $2069(856-5004)$ & $172(105-280)^{* *}$ & $242(120-486)$ \\
& AZA & $514(460-574)$ & $317(289-347)^{* *}$ & $266(237-298)^{*}$ \\
& 6-MP & n.r. & $679(502-920)$ & $412(321-530)$ \\
& TG & $1949(993-3827)$ & $100^{* *}(80-125)$ & $19 * *(16-22)$ \\
& 5-ASA & n.r. & n.r. & n.r. \\
& Allopurinol & n.r. & $999(766-1302)^{* *}$ & $509(411-631)^{* *}$ \\
\hline
\end{tabular}




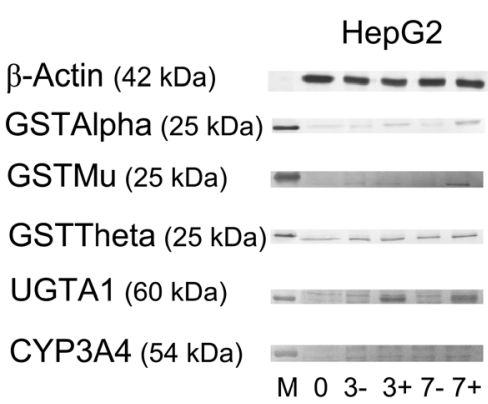

Fig. 3 Expression of $\beta$-actin, GSTAlpha, GSTMu, GSTTheta, CYP3A4 and UGT1A in HepG2, Huh7 and HepaRG cells at day 0 , after 3 days of incubation with William's E medium without DMSO (3-) or William's with DMSO $2 \%(3+)$ and after 7 days of incubation without (7-) and with (7+) DMSO. $M$ rainbow marker (Precision Plus Protein $^{\mathrm{TM}}$ Kaleidoscope ${ }^{\mathrm{TM}}$ ) or antigen for the

\section{Comet assay}

The comet assay was used to identify the mechanisms behind the increased toxicity with allopurinol co-administration. This assay was performed according to the manufacturer's instructions (Trevigen Inc., Gaithersburg, MD). HepaRG cells were seeded in $25-\mathrm{cm}^{2}$ flasks and treated $24 \mathrm{~h}$ with allopurinol $(100 \mu \mathrm{M})$, AZA $(70 \mu \mathrm{M})$, AZA $(70 \mu \mathrm{M})+$ allopurinol $(100 \mu \mathrm{M})$ or untreated (control). After $24 \mathrm{~h}$, cells were harvested and the cell suspension was mixed with $75 \mu \mathrm{L}$ low melting agarose (Trevigen Inc.) in a density of $2 \times 10^{4}$ cells $/ \mathrm{mL}$ and directly pipetted on agarose-precoated slides. Slides were stored at $4{ }^{\circ} \mathrm{C}$ for $30 \mathrm{~min}$ and subsequently submerged in lysis solution. After 60-min lysis, they were treated with alkaline unwending solution $(\mathrm{pH}>13)$ for $60 \mathrm{~min}$, followed by 30 -min electrophoresis at $25 \mathrm{~V}$. Slides were stained with SYBR green (Trevigen Inc.) and visualised and photographed by a digital camera (AxioCam MRm)

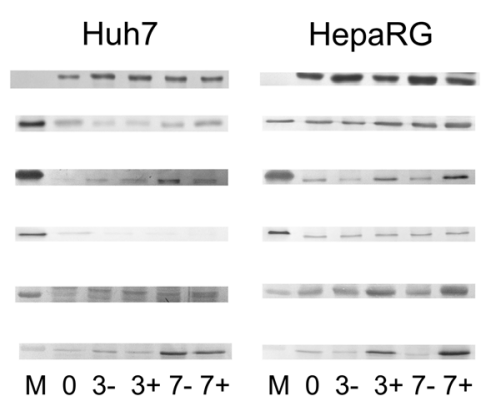

specific antibody (GST Alpha, Mu and Theta). GSTAlpha glutathione S-transferase alpha, GSTMu glutathione S-transferase $\mathrm{Mu}$, GSTTheta glutathione S-transferase Theta, CYP3A4 cytochromeP450 3A4, UGT1A UDP-glucuronosyltransferase 1A, DMSO dimethyl sulfoxide

attached to a fluorescent microscope (Axio imager.M1) using a $20 \times$ magnification.

\section{Statistics}

For the cytotoxicity analyses, the mean absorption of the empty wells was used to correct for background staining. The mean of three experiments was used for further calculations. Cell survival (in percentage of control) was calculated by dividing the mean of each concentration by the mean of the control wells (cells without drugs). Half maximal inhibitory concentrations $\left(\mathrm{IC}_{50}\right)$ were calculated and subsequently tested among experiments using the extra sum of squares $F$ test. Differences in caspase-3/7 activation were compared means of the by Mann-Whitney $U$ test. Analyses were performed with GraphPad Prism (version 5.03 for Windows, GraphPad Software, San Diego, California, USA; www.graphpad.com).
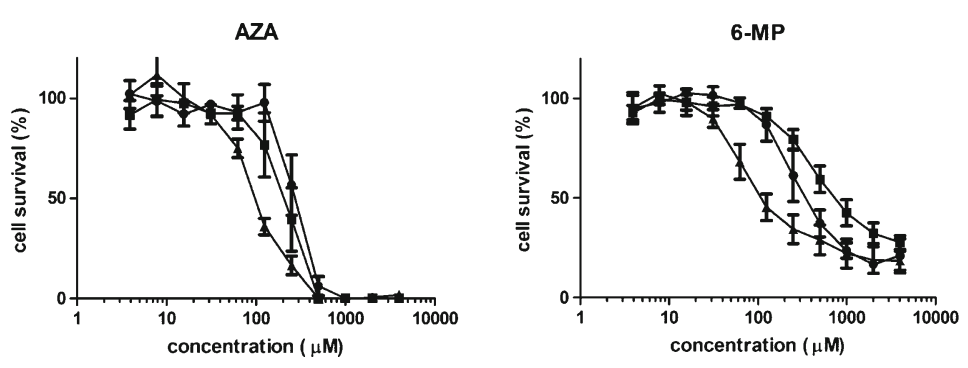

TG

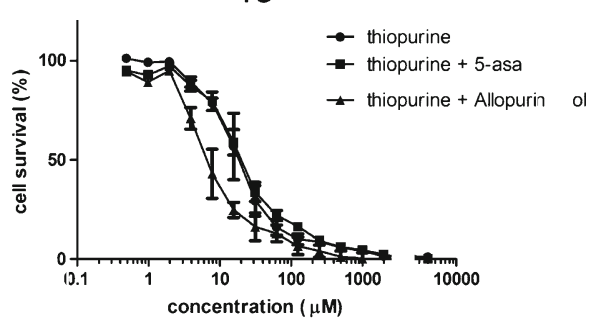

Fig. 4 Cell survival curves after incubation of HepaRG cells with AZA, 6-MP or TG for $72 \mathrm{~h}$ with and without a fixed non-toxic concentration of $200 \mu \mathrm{M}$ 5-ASA or $100 \mu \mathrm{M}$ allopurinol. Values are means with SEM from three independent experiments, performed in triplicate. $A Z A$ azathioprine, 6-MP 6-mercaptopurine, $T G$ thioguanine, 5-ASA 5-aminosalicylic acid, SEM standard error of the mean 


\section{Results}

Single-drug tests

AZA showed a steep decline in cell survival at concentrations above approximately $200 \mu \mathrm{M}$ in all cell lines (Fig. 2), with a time-dependent effect (Table 1). With respect to 6-MP, cell survival was not affected in the HepG2 and Huh7 cells; however, in the HepaRG cells, a decline in cell survival was seen when incubating for 48 or $72 \mathrm{~h}$ (Table 1). Incubation with TG resulted in a dosedependent decline of cell survival observed in all cell lines, with the most pronounced decline in HepaRG cells. The lowest $\mathrm{IC}_{50}$ value (i.e. most cytotoxicity) was found in the HepaRG cells incubated for $72 \mathrm{~h}$ with $\mathrm{TG}$, with an $\mathrm{IC}_{50}$ of $19 \mu \mathrm{M}$ (Table 1).

\section{Expression of drug metabolising enzymes}

Large differences were seen between the three cell lines regarding the expression of UGT1A, CYP3A4, GSTAlpha, GSTMu and GSTTheta (Fig. 3). Huh7 and HepaRG cells showed CYP3A4 expression, whereas HepG2 cells did not. The HepaRG cells showed the highest expression of GSTAlpha and GSTMu. GSTTheta was expressed in both HepaRG and HepG2 cells but not at all in Huh7 cells. The latter was confirmed by PCR analysis, which showed a GSTT1 gene deletion in Huh7 cells (data not shown). In HepG2 and Huh7 cells, addition of DMSO to the culture medium increased the expression of GST and UGTA1 enzymes. Overall, HepaRG cells showed the highest expression of all enzymes.

Combination tests of thiopurines with 5-ASA or allopurinol

Based on the highest expression of drug metabolising enzymes, HepaRG cells were used for the combination experiments with 5-ASA and allopurinol. 5-ASA did not influence cell survival of HepaRG cells at all, while incubation with allopurinol gave a decline in cell survival after 48 and $72 \mathrm{~h}$ with concentrations above $300 \mu \mathrm{M}$ (Fig. 2 and Table 1). As can be seen in Fig. 4 and Table 2, incubation of thiopurines in combination with a fixed, non-toxic dose of $100 \mu \mathrm{M}$ allopurinol had a larger influence on cytotoxicity than concomitant incubation with $200 \mu \mathrm{M}$ 5-ASA. Co-administration of allopurinol with all thiopurines consistently resulted in

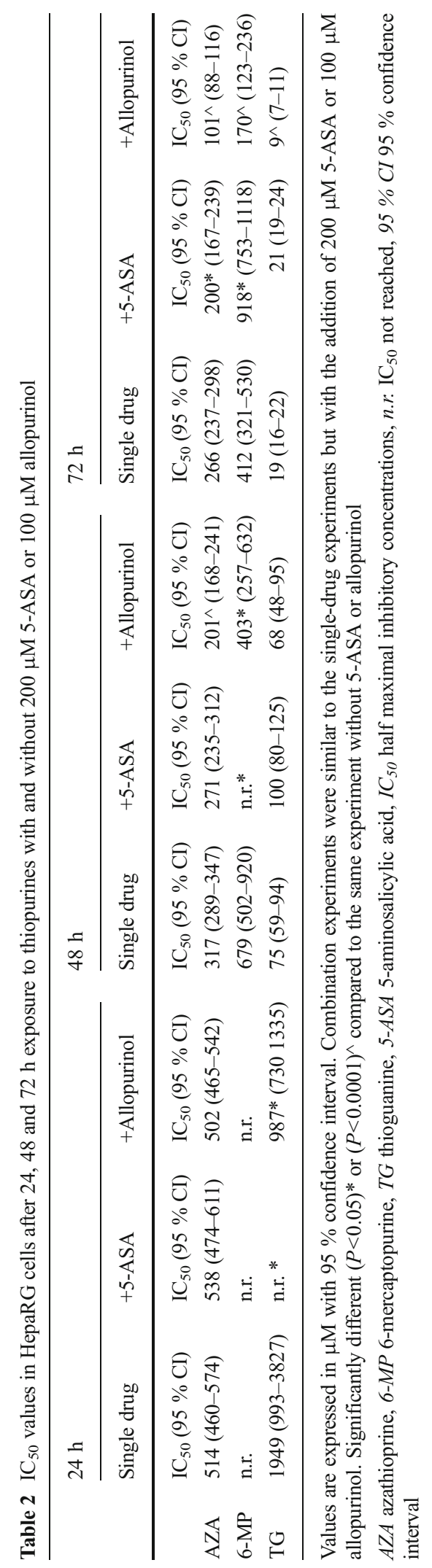


an increased cytotoxicity, with the most pronounced cytotoxic effects emerging after 48 or $72 \mathrm{~h}$. The combination of 6-MP and 5-ASA but not AZA and 5-ASA showed an increase in $\mathrm{IC}_{50}$ (i.e. decreased cytotoxicity) after 48 or $72 \mathrm{~h}$ incubation.

TPMT activity and genotype

No mutations were found for the three most common allele variants in TPMT. TPMT activity was expressed as nmol 6-methylthioguanine/mg protein per hour and was lowest in HepG2 cells $(0.08 \mathrm{nmol} /$ $\mathrm{mg}$ protein per hour), followed by HepaRG cells (0.28 nmol/mg protein per hour) and Huh7 cells ( $0.47 \mathrm{nmol} / \mathrm{mg}$ protein per hour). Values were comparable with these found in other cell lines (Karim et al. 2013). TPMT activity was not correlated with the cytotoxicity.

\section{Metabolite formation}

Support for in vitro metabolism of the thiopurines was obtained by HPLC. The retention time of 6-TGN was comparable to AZA and 6-MP; therefore, only 6-MMP metabolites could be identified by HPLC. In the culture medium of HepaRG cells incubated with AZA, we demonstrated the presence of 6-MMP metabolites, providing evidence for in vitro metabolism of AZA in HepaRG cells (Fig. 5).

Mechanisms behind the increased cytotoxicity of allopurinol co-administration

DNA damage by AZA with or without allopurinol was visualised with single cell electrophoreses (Fig. 6). With levels of AZA $(70 \mu \mathrm{M})$ not affecting cell viability, the combination of AZA+allopurinol resulted in larger comet tails (more DNA damage) than incubation with AZA alone. In addition, caspase-3/7 activation was significantly increased $(P<0.01)$ when allopurinol $(100 \mu \mathrm{M})$ was coadministered with AZA $(70 \mu \mathrm{M})$, while allopurinol alone did not increase caspase-3/7 activation (Fig. 7). Co-administration of 5-ASA $(200 \mu \mathrm{M})$ with AZA $(70 \mu \mathrm{M})$ did not influence caspase-3/7 activation $(P=0.17)$.
Culture Medium HepaRG cells

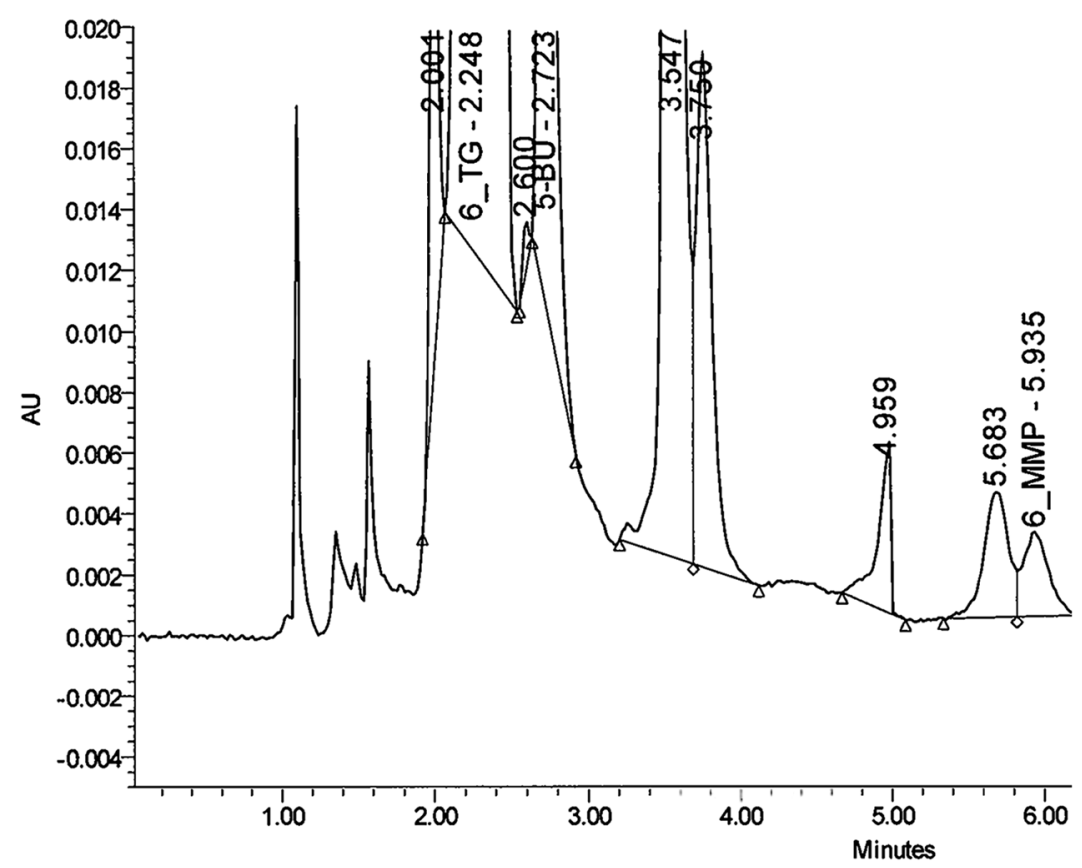

Standard

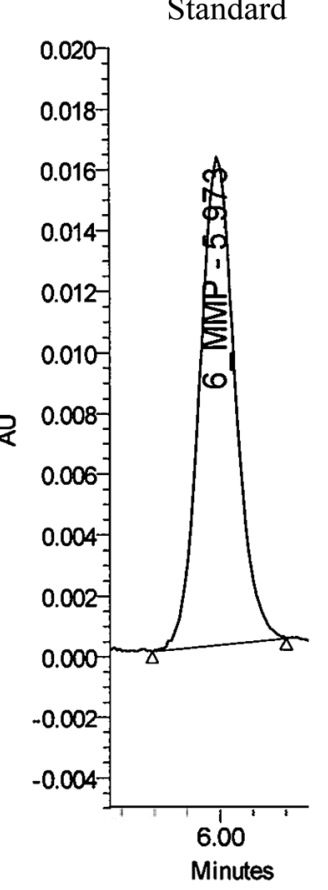

Fig. 5 Formation of 6-MMP (RT: 5.935) metabolites, measured by HPLC in culture medium of HepaRG cells after incubation with AZA for $10 \mathrm{~h}$. The RT of AZA and 6-MP is equal to that of 6TGN; therefore, only 6-MMP metabolites could be distinguished.
Other peaks are substances of culture medium. 6-MMP 6methylmercaptopurine, $R T$ retention time, $A Z A$ azathioprine, 6$M P$ 6-mercaptopurine, 6-TGN thioguanine nucleotide 

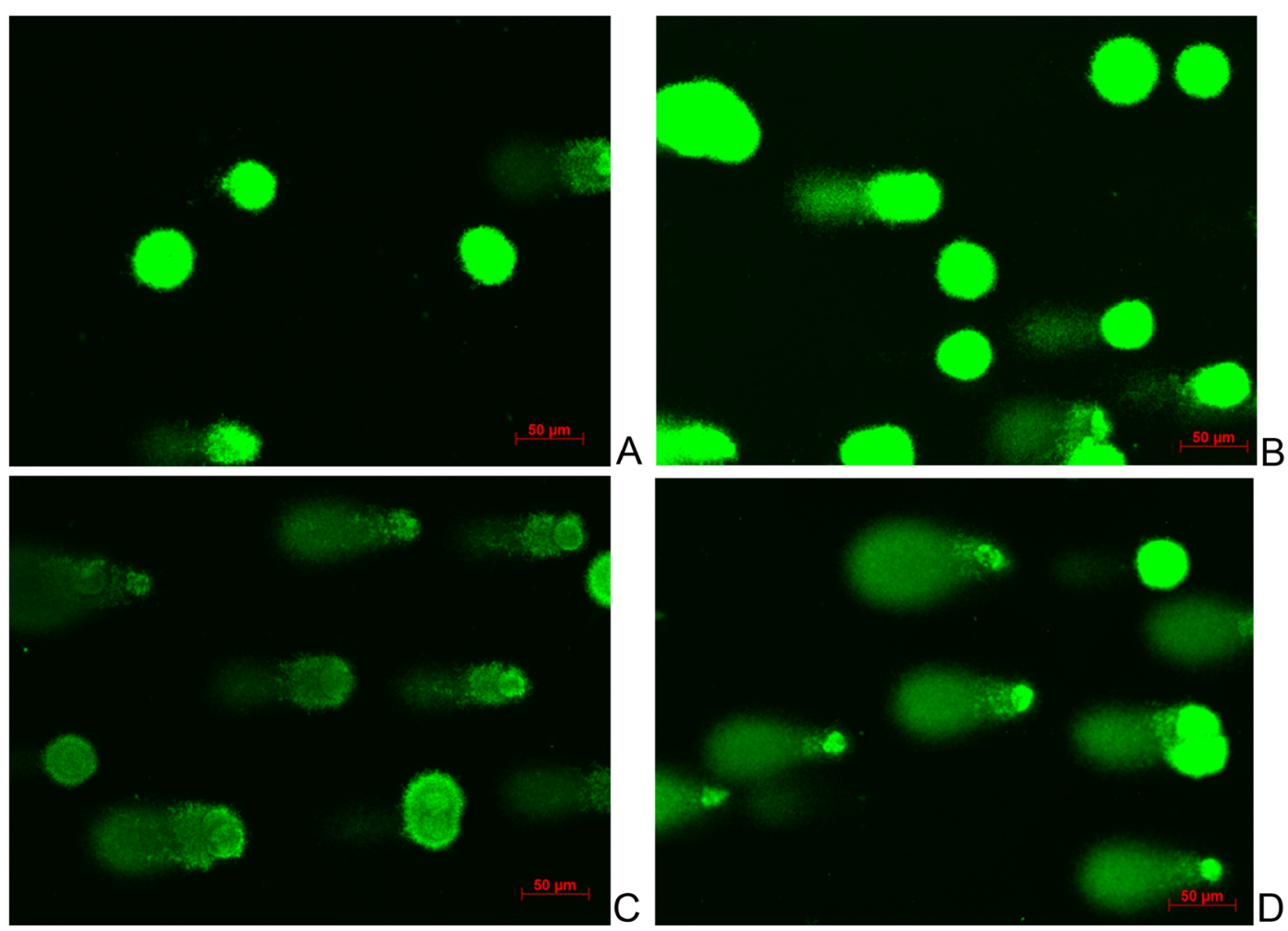

Fig. 6 Single cell gel electrophoresis (Comet assay) of HepaRG cells incubated with a medium serving as control, b allopurinol $(100 \mu \mathrm{M})$, c AZA $(70 \mu \mathrm{M})$ and d AZA $70(\mu \mathrm{M})$ and allopurinol $(100 \mu \mathrm{M})$. HepaRG cells were embedded in low melting agarose on a slide, then lysed and treated with alkaline for DNA

unwending followed by alkaline electrophoresis $(\mathrm{pH}>13)$. Following SYBR Green I staining, nuclei were visualised under an epifluorescence microscope. Damaged DNA migrates towards the anode, resulting in a comet tail. $A Z A$ azathioprine

\section{Discussion}

In this study, we showed that the combination of a nontoxic dose of $100 \mu \mathrm{M}$ allopurinol with AZA, 6-MP or TG led to a twofold to threefold increase in thiopurineinduced cytotoxicity in HepaRG cells. The most likely explanation for the increased cytotoxicity with allopurinol is an elevation of 6-TGN levels, which are incorporated into DNA as fraudulent bases, resulting in strand breakage and apoptosis (Sahasranaman et al. 2008).

Previous studies in cultures of rat hepatocytes showed a positive effect on cell viability when allopurinol was co-administered with AZA, due to its antioxidant capacities (Lee and Farrell 2001; Tapner et al. 2004; Al Maruf et al. 2014). The contrasting findings of our study might be explained by differences in the experimental settings. Isolated rat hepatocytes exert no mitotic activity in contrast to human hepatoma cells. Because 6-TGNs act through incorporation into the DNA, this effect may be more pronounced in mitotically

active cells. We hypothesise that the higher levels of 6TGNs with allopurinol co-administration are responsible for the increased cytotoxicity. This is supported by our findings that allopurinol co-administration resulted in more single-strand breakages and significant increased caspase-3/7 activation. In vivo, coadministration of allopurinol results in a significant reduction of 6-MMP metabolites and increase of 6TGN metabolites (Hoentjen et al. 2013). Unfortunately, we were not able to analyse 6-TGN levels by HPLC, because of equal retention times of AZA, 6-MP and 6TGN. A direct comparison of our in vitro study with in vivo situation is difficult because of low mitotic activity of human hepatocytes compared with our human hepatoma cells. However, HepaRG cells are known to have decreased mitotic activity when they are confluent, resembling the in vivo situation as best as possible. (Andersson et al. 2012).

Theoretically, addition of 5-ASA may lead to decreased hepatotoxicity in vivo by inhibition of TPMT, 


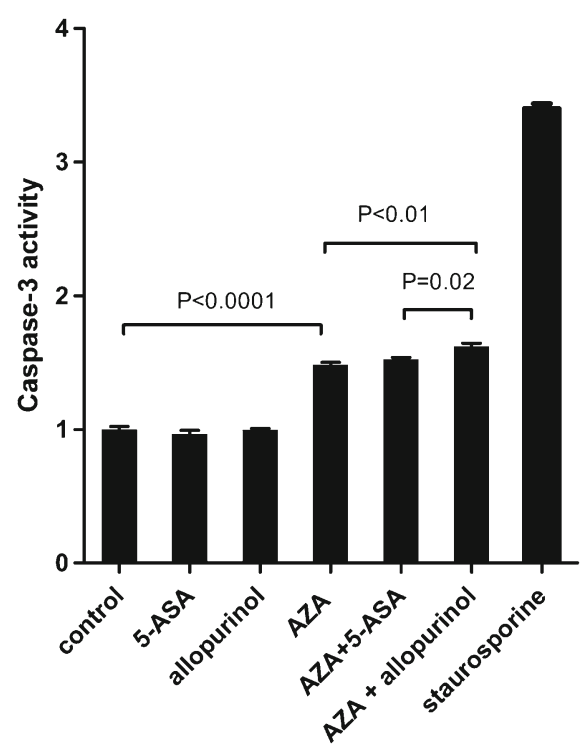

Fig. 7 Caspase-3/7 activation of HepaRG cells incubated $24 \mathrm{~h}$ with medium (control), 5-ASA $(200 \mu \mathrm{M})$, allopurinol $(100 \mu \mathrm{M})$, AZA $(70 \mu \mathrm{M})$ or a combination of both. Staurosporine $(2 \mu \mathrm{M})$ was used as positive control. Activation of cells incubated only with medium was set as control. Values are presented as mean of two experiments with the SEM. Differences were compared with the Mann-Whitney $U$ test. $A Z A$ azathioprine, 5-ASA 5aminosalicylic acid, $S E M$ standard error of the mean

leading to a decline in 6-MMP levels (Szumlanski and Weinshilboum 1995; Dubinsky et al. 2000; de Graaf et al. 2010). However, there is much debate about the clinical significance of this interaction (Actis et al. 2009). The interaction between 5-ASA and thiopurines is non-competitive, and long-term 5-ASA therapy did not affect TPMT enzyme activity in a prospective study in CD patients (Szumlanski and Weinshilboum 1995; Dilger et al. 2007). Unfortunately, measurement of 5ASA influences on TPMT activity is technically not feasible to our knowledge, because 5-ASA is removed in the washing steps (Dilger et al. 2007). In our in vitro study, the effects of 5-ASA on cytotoxicity were limited compared to allopurinol. This is supported by the finding that 5-ASA co-administration did not increase caspase- $3 / 7$ activation.

In this study, we showed that concentration-based TG is more cytotoxic than AZA or 6-MP, with $\mathrm{IC}_{50}$ values of $18 \mu \mathrm{M}$ in HepaRG cells after 72-h incubation. This probably results from a direct conversion of 6-TG to 6-TGN, resulting in higher 6-TGN levels and less other metabolites. The increased cytotoxicity of TG with allopurinol co-administered can be explained by XO involvement in TG metabolism (Fig. 1). Our results of single-drug assessments of AZA and 6-MP in HepaRG cells are in accordance with those of Petit et al., who compared HepaRG cells with human hepatocytes (Petit et al. 2008). Furthermore, we showed a different toxicity profile of AZA and 6-MP in Huh7 and HepG2 cells. This might be explained by depletion of glutathione, caused by the conversion of AZA to 6-MP, as previously shown by Lee and Farrell (Lee and Farrell 2001). On the other hand, in HepaRG cells, this difference was not that prominent.

We measured both TPMT activity as well as the most prevalent polymorphisms in the TPMT gene (TPMT*2 and TPMT*3A, *3B), because TPMT activity still varies in patients without these polymorphisms (Lennard 2013). Low TPMT activity is associated with high 6-TGN levels, which may cause leucopenia (Shaye et al. 2007; Lennard 2013). The three hepatoma cell lines tested had identical TPMT genotypes, but a variance in TPMT activity was noticed. Hence, no direct relation with cytotoxicity was found. It is difficult to compare TPMT activity we measured with those in clinical studies as herein TPMT activity is measured in erythrocytes (Ford and Berg 2003).

Unfortunately, our HPLC method could not discriminate 6-TGN from AZA or 6-MP. This would be of particular interest, as that would allow the production of a dose response curve comparing the association between 6-TGN levels and cytotoxicity. Despite the fact that the used HPLC protocol was not intended and validated for cell line research, our study is still unique, providing direct evidence of the in vitro metabolism of AZA in the HepaRG cell line demonstrated by the formation of 6-MMP. Another limitation of this study is the lack of comparison with human hepatocytes. It has to be stressed that incubation experiments with human hepatocytes also have their limitations, as human hepatocytes are difficult to obtain and their metabolic activities rapidly decline during culturing (Gomez-Lechon et al. 2003; Guillouzo et al. 2007; Szabo et al. 2013). HepaRG cells are currently considered as the best surrogate for human hepatocytes for use in drug toxicity studies and are closer related to human hepatocytes than rat hepatocytes because of the high conservation of metabolic enzymes and the absence of interspecies differences (Parent et al. 2004; Guillouzo et al. 2007; Hart et al. 2010; Andersson et al. 2012; Szabo et al. 2013). With the notion that HepG2 and Huh7 cells have been used more extensively in in vitro experiments so far, we 
also used these cell lines for comparison (Guo et al. 2011). In accordance with previous studies (Petit et al. 2008; Hart et al. 2010; Andersson et al. 2012), we showed that HepaRG cells express the highest levels of important drug metabolising enzymes. In order to create similar experimental conditions for the three cell lines, we used the same culture medium for all three cell lines, which includes addition of $2 \%$ DMSO according to the HepaRG culturing protocol (Gripon et al. 2002). DMSO is used to induce or maintain cell differentiation in HepaRG cells (Gripon et al. 2002; Narimatsu et al. 2006; Sainz and Chisari 2006; Choi et al. 2009). Because previous studies with HepG2 and Huh7 cells did not use DMSO, this can be considered as a limitation. However, our results demonstrate that the upregulation of drug metabolising enzymes by DMSO is not limited to HepaRG cells, results which are in accordance with those of Choi et al. (Choi et al. 2009).

In conclusion, in this in vitro study, we could demonstrate a considerable increase of thiopurine-induced cytotoxicity by co-treatment with a non-toxic dose of allopurinol.

Acknowledgments We thank Marieke Coenen, Department of Human Genetics, Radboud University Medical Centre, the Netherlands, for analysing TPMT genotypes and Jean Cilissen, Department of Clinical Pharmacy \& Toxicology, Orbis Medical Centre, Sittard-Geleen, the Netherlands for assistance with measurement of thiopurine metabolites.

\section{Conflicts of interest None.}

Open Access This article is distributed under the terms of the Creative Commons Attribution 4.0 International License (http:// creativecommons.org/licenses/by/4.0/), which permits unrestricted use, distribution, and reproduction in any medium, provided you give appropriate credit to the original author(s) and the source, provide a link to the Creative Commons license, and indicate if changes were made.

\section{References}

Actis GC, Pellicano R, et al. Individually administered or coprescribed thiopurines and mesalamines for inflammatory bowel disease. World J Gastroenterol. 2009;15(12):1420-6.

Al Maruf A, Wan L, et al. Evaluation of azathioprine-induced cytotoxicity in an in vitro rat hepatocyte system. Biomed Res Int. 2014;2014:379748.
Andersson TB, Kanebratt KP, et al. The HepaRG cell line: a unique in vitro tool for understanding drug metabolism and toxicology in human. Expert Opin Drug Metab Toxicol. 2012;8(7):909-20.

Blaker PA, Arenas-Hernandez M, et al. Mechanism of allopurinol induced TPMT inhibition. Biochem Pharmacol. 2013;86(4): 539-47.

Choi S, Sainz Jr B, et al. Characterization of increased drug metabolism activity in dimethyl sulfoxide (DMSO)-treated Huh7 hepatoma cells. Xenobiotica. 2009;39(3):205-17.

de Graaf P, de Boer NK, et al. Influence of 5-aminosalicylic acid on 6-thioguanosine phosphate metabolite levels: a prospective study in patients under steady thiopurine therapy. Br J Pharmacol. 2010;160(5):1083-91.

de Vries HS, de Heij T, et al. Infliximab exerts no direct hepatotoxic effect on HepG2 cells in vitro. Dig Dis Sci. 2012;57(6): 1604-8.

Dervieux T, Boulieu R. Simultaneous determination of 6thioguanine and methyl 6-mercaptopurine nucleotides of azathioprine in red blood cells by HPLC. Clin Chem. 1998;44(3):551-5.

Dewit O, Vanheuverzwyn R, et al. Interaction between azathioprine and aminosalicylates: an in vivo study in patients with Crohn's disease. Aliment Pharmacol Ther. 2002;16(1): 79-85.

Dilger K, Schaeffeler E, et al. Monitoring of thiopurine methyltransferase activity in postsurgical patients with Crohn's disease during 1 year of treatment with azathioprine or mesalazine. Ther Drug Monit. 2007;29(1):1-5.

Dubinsky MC, Lamothe S, et al. Pharmacogenomics and metabolite measurement for 6-mercaptopurine therapy in inflammatory bowel disease. Gastroenterology. 2000;118(4):705-13.

Eklund BI, Moberg M, et al. Divergent activities of human glutathione transferases in the bioactivation of azathioprine. Mol Pharmacol. 2006;70(2):747-54.

Ford LT, Berg JD. Determination of thiopurine S-methyltransferase activity in erythrocytes using 6-thioguanine as substrate and a non-extraction liquid chromatographic technique. J Chromatogr B Analyt Technol Biomed Life Sci. 2003;798(1):111-5.

Gomez-Lechon MJ, Donato MT, et al. Human hepatocytes as a tool for studying toxicity and drug metabolism. Curr Drug Metab. 2003;4(4):292-312.

Gripon P, Rumin S, et al. Infection of a human hepatoma cell line by hepatitis B virus. Proc Natl Acad Sci U S A. 2002;99(24): 15655-60.

Guillouzo A, Corlu A, et al. The human hepatoma HepaRG cells: a highly differentiated model for studies of liver metabolism and toxicity of xenobiotics. Chem Biol Interact. 2007;168(1): 66-73.

Guo L, Dial S, et al. Similarities and differences in the expression of drug-metabolizing enzymes between human hepatic cell lines and primary human hepatocytes. Drug Metab Dispos. 2011;39(3):528-38.

Hart SN, Li Y, et al. A comparison of whole genome gene expression profiles of HepaRG cells and HepG2 cells to primary human hepatocytes and human liver tissues. Drug Metab Dispos. 2010;38(6):988-94.

Hoentjen F, Seinen ML, et al. Safety and effectiveness of long-term allopurinol-thiopurine maintenance treatment in inflammatory bowel disease. Inflamm Bowel Dis. 2013;19(2):363-9. 
Karim H, Appell ML, et al. Comparison of three methods for measuring thiopurine methyltransferase activity in red blood cells and human leukemia cells. J Chromatogr B Analyt Technol Biomed Life Sci. 2013;939:80-5.

Lee AU, Farrell GC. Mechanism of azathioprine-induced injury to hepatocytes: roles of glutathione depletion and mitochondrial injury. J Hepatol. 2001;35(6):756-64.

Lennard L. Implementation of TPMT testing. Br J Clin Pharmacol. 2013;77(4):704-14.

Lowry OH, Rosebrough NJ, et al. Protein measurement with the Folin phenol reagent. J Biol Chem. 1951;193(1):265-75.

Lowry PW, Franklin CL, et al. Leucopenia resulting from a drug interaction between azathioprine or 6-mercaptopurine and mesalamine, sulphasalazine, or balsalazide. Gut. 2001;49(5):656-64.

Narimatsu S, Takatsu N, et al. The effect of dimethyl sulfoxide on the function of cytochrome P450 2D6 in HepG2 cells upon the co-expression with NADPH-cytochrome P450 reductase. Chem Biol Interact. 2006;159(1):47-57.

Parent R, Marion MJ, et al. Origin and characterization of a human bipotent liver progenitor cell line. Gastroenterology. 2004;126(4):1147-56.

Peters WH, Allebes WA, et al. Characterization and tissue specificity of a monoclonal antibody against human uridine 5'diphosphate-glucuronosyltransferase. Gastroenterology. 1987;93(1):162-9.

Peters WH, Kock L, et al. Immunodetection with a monoclonal antibody of glutathione S-transferase mu in patients with and without carcinomas. Biochem Pharmacol. 1990;39(3):591-7.
Peters WH, Boon CE, et al. Expression of drug-metabolizing enzymes and P-170 glycoprotein in colorectal carcinoma and normal mucosa. Gastroenterology. 1992;103(2): 448-55.

Petit E, Langouet S, et al. Differential toxic effects of azathioprine, 6-mercaptopurine and 6-thioguanine on human hepatocytes. Toxicol In Vitro. 2008;22(3):632-42.

Sahasranaman S, Howard D, et al. Clinical pharmacology and pharmacogenetics of thiopurines. Eur J Clin Pharmacol. 2008;64(8):753-67.

Sainz Jr B, Chisari FV. Production of infectious hepatitis C virus by well-differentiated, growth-arrested human hepatomaderived cells. J Virol. 2006;80(20):10253-7.

Shaye OA, Yadegari M, et al. Hepatotoxicity of 6-mercaptopurine (6-MP) and Azathioprine (AZA) in adult IBD patients. Am J Gastroenterol. 2007;102(11):2488-94.

Szabo M, Veres Z, et al. Comparison of human hepatoma HepaRG cells with human and rat hepatocytes in uptake transport assays in order to predict a risk of drug induced hepatotoxicity. PLoS One. 2013;8(3):e59432.

Szumlanski CL, Weinshilboum RM. Sulphasalazine inhibition of thiopurine methyltransferase: possible mechanism for interaction with 6-mercaptopurine and azathioprine. Br J Clin Pharmacol. 1995;39(4):456-9.

Tapner MJ, Jones BE, et al. Toxicity of low dose azathioprine and 6-mercaptopurine in rat hepatocytes. Roles of xanthine oxidase and mitochondrial injury. J Hepatol. 2004;40(3): 454-63. 